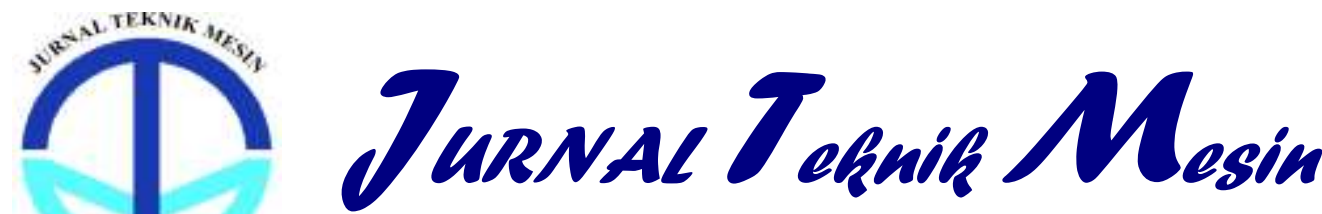

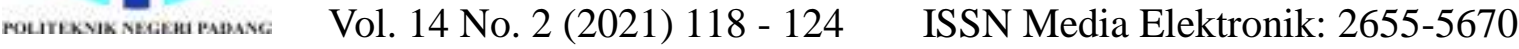

\section{Perancangan Bilah Turbin Angin Jenis Taperless Untuk Pesisir Pantai Utara Jawa Barat Menggunakan Perangkat Lunak QBlade}

\author{
Shinta Dwi Oktaviani ${ }^{1}$, Reza Setiawan ${ }^{2}$, Farradina Choria Suci ${ }^{3}$ \\ Teknik Mesin, Universitas Singaperbangsa Karawang \\ ${ }^{1}$ shintad.oktaviani80@gmail.com’ ${ }^{2}$ reza.setiawan@ft.unsika.ac.id ${ }^{3}$ farradina.cs@ ft.unsika.ac.id
}

\begin{abstract}
Energy needs in Indonesia continue to increase, while the availability of non-renewable energy sources is decreasing and is exacerbated by the increasing use of fuels that are not environmentally friendly, so efforts are needed to find alternative uses of renewable energy that are renewable and environmentally friendly. The Cirebon coast has good wind conditions which can be used to create renewable energy sources through the wind. This study aims to utilize the energy that is already available by designing a horizontal wind turbine blade. The method used starts from literature study, selecting airfoils, analyzing data, selecting the best airfoils, analyzing the best airfoils and ending with design drawings. The initial data used as the initial design is the Cirebon City wind data which has the highest average wind speed of $9 \mathrm{~m} / \mathrm{s}$. This study designed a horizontal wind turbine blade using QBlade Software with 3 types of NACA, NACA 4415, 6412 and 6415. NACA 6415 has a power coefficient of $0.40 \%$, the highest coefficient is then obtained NACA 6412 with a coefficient of $0.41 \%$, and The highest power coefficient was obtained by NACA 4415 with a coefficient of $44 \%$.
\end{abstract}

Keywords : NACA, airfoil, power coefficient, TSR, QBlade

\begin{abstract}
Abstrak
Kebutuhan energi di Indonesia terus meningkat, sedangkan ketersediaan sumber energi tidak terbarukan semakin berkurang juga dengan meningkatnya penggunaan bahan bakar yang tidak ramah lingkungan, sehingga diperlukan upaya untuk mencari alternatif penggunaan energi terbarukan yang bersifat renewable dan ramah lingkungan. Pesisir Cirebon memiliki kondisi angin yang baik dapat dimanfaatkan untuk menciptakan sumber energi terbarukan melalui angin. Penelitian ini bertujuan untuk memanfaatkan energi yang sudah tersedia dengan merancang bilah turbin angin horizontal. Metode yang digunakan dimulai dari studi literatur, memilih airfoil, analisa data, memilih airfoil terbaik, menganalisis airfoil terbaik dan berakhir dengan gambar desain. Data awal yg digunakan sebagai awal perancangan adalah data angin Kota Cirebon yang memiliki rata-rata kecepatan angin tertinggi $9 \mathrm{~m} / \mathrm{s}$. Penelitian ini merancang bilah turbin angin horizontal dengan menggunakan Software QBlade dengan 3 jenis NACA, NACA 4415, 6412 dan 6415. NACA 6415 memiliki hasil koefisien daya sebesar $0,40 \%$, koefieien tertinggi selanjutnya diperoleh NACA 6412 dengan koefisiensi sebesar 0,41\%, dan koefisien daya tertinggi diperoleh NACA 4415 dengan hasil koefisiensi sebesar $44 \%$.
\end{abstract}

Kata kunci : NACA, airfoil, koefisien daya, TSR, QBlade

\section{Pendahuluan}

Energi merupakan konstituen pembangunan sosial dan pertumbuhan ekonomi paling besar. Pengunaan bahan bakar fosil memiliki presentase paling besar sebagai energi yang paling banyak digunakan dan tidak dapat diperbarui sehingga ketersediaannya semakin berkurang. Bahan bakar fossil saat terjadi pembakaran akan melepaskan gas dan partikel halus yang berbahaya. Gas ini tidak hanya mencemari lingkungan, tetapi juga membahayakan makhluk bumi dan tidak dapat diperbarui. Sumber energi yang digunakan selama ini dapat menyebabkan pencemaran lingkungan dan kerusakan lingkungan berupa perubahan iklim dan efek gas rumah kaca di atmosfer [2]. Hal tersebutlah yang mengubah paham banyak 
negara untuk beralih menggunakan energi yang terbarukan secara bertahap untuk memanfaatkan energi yang sudah tersedia agar nantinya tidak ada lagi kelangkaan energi.

Angin merupakan udara yang bergerak diakibatkan karena rotasi bumi dan juga karena adanya perbedaan tekanan udara disekitarnya [3]. Angin mempunyai hubungan yang erat dengan sinar matahari, dikarenakan tempat yang memiliki suhu tinggi dan memiliki tekanan udara rendah dapat menyebabkan terjadinya aliran udara. Pada permukaan bumi kecepatan relatif angin adalah nol, kemudian kecepatan angin menjadi semakin tinggi seiring bertambah tingginya permukaan bumi. Radiasi matahari yang memanas dengan kecepatan berbeda di berbagai belahan bumi menyebabkan berbagai bagian atmosfer memanas dalam waktu yang berbeda. Udara panas naik dan udara yang lebih sejuk tertarik untuk mengantikannya, jadi angin yang disebabkan oleh molekul udara di atmosfer berasal dari energi matahari.

Energi angin adalah salah satu energi terbarukan yang cukup ramah lingkungan, berlimpah dan juga dapat terbarukan atau bersifat renewable, selain itu Indonesia juga memiliki potensi energi angin yang dapat dimanfaatkan dengan baik. Indonesia memiliki wilayah yang $2 / 3$ nya merupakan wilayah lautan. Secara keseluruhan, potensi energi angin di Indonesia tidak terlalu besar karena rata- rata kecepatan angin tahunan hanya sebesar 3,5-4,5 m/s [4]. Tetapi potensi angin tersebut sudah cukup untuk digunakan sebagai pembangkit energi listrik skala kecil hingga $10 \mathrm{~kW}$ [5]. Turbin angin merupakan alat konversi yang dapat mengubah energi kinetik menjadi energi mekanik, dimana turbin digerakkan oleh angin yang kemudian melalui generator dapat diubah menjadi energi listrik. Salah satu turbin angin yang memiliki efisiensi tinggi adalah turbin angin jenis horzontal dengan menggunakan jenis bilah yang memiliki koefisien daya (Cp) cukup tinggi mendekati $45 \%$ yaitu tipe Blade Propeller [6]

Turbin angin dapat dibagi menjadi dua kelompok utama berdasarkan arah sumbu turbin yaitu sumbu horizontal dan sumbu vertikal. Turbin angin jenis horizontal adalah turbin angin yang berputar mengelilingi sumbu horizontal, memiliki bilah yang menghasilkan aerodynamic lift pada saat angin melewatinya dan hanya dapat memanfaatkan aliran udara dari satu arah. Bilah turbin angin horizontal dibuat kaku agar tidak mendorong maju menara angin ketika ada angin berkecepatan tinggi. Bilah jenis taperless merupakan jenis bilah yang memiliki bentuk penampang sama dari pangkal hingga ujung. Sudu bilah jenis taperless lebih awal berputar daripada sudu jenis lainnya karena angin yang menerpa penampang sudu lebih banyak dan merata [7]. Wilayah yang memiliki kecepatan angin rendah didefinisikan sebagai ladang angin yang dengan kecepatan angin rata-rata tahunan dibawah $5,8 \mathrm{~m} / \mathrm{s}$ pada ketinggian 10m [8]. Dari data pemerintah provinsi Jawa Barat, Kota Cirebon terletak pada $108^{\circ} 33$ Bujur Timur dan $6^{\circ} 41$ Lintang Selatan pada pantai Utara Pulau Jawa, bagian timur Jawa Barat, memanjang dari barat ke timur kurang lebih $11 \mathrm{Km}$ dengan ketinggian dari permukaan laut $5 \mathrm{M}$. Luas kota Ciebon adalah 3.735,82 hektar atau kurang lebih $37 \mathrm{Km}^{2}$ dengan dominasi penggunaan lahan perumahan (32\%) dan tanah pertanian 38\% [9]. Kota Cirebon berada di wilayah pantai utara Jawa Barat yang membuat wilayah Kota Cirebon memiliki dataran yang lebih luas dibanding wilayah perbukitannya. Wilayah Kotamadya Cirebon dibatasi oleh Sungai Kedung Pane di Utara, sungan banjir kanan di timur, Sungai kalijaga di selatan, dan Laut Jawa di sebelah timur. Sebagian wilayahnya merupakan dataran rendah dengan ketinggian antara 0-2000 dpl, sementara kemiringan lereng antara $0-40 \%$ dimana $0-3 \%$ merupakan daerah berkarakteristik kota, 3-25\% daerah transmisi dan 25-40\% merupakan pinggiran [10]. Kota Cirebon memiliki rata-rata kecepatan angin yang cukup memadai untuk didirikannya sebuah turbin angin skala kecil. Gunanya untuk memberdayakan kecepatan angin yang ada di pesisir Kota Cirebon dan membantu mengedukasi masyarakat untuk bisa mengurangi penggunaan energi fosil dan mulai beralih menggunakan energi terbarukan. Selain itu, tempat pembangunan turbin angin nantinya bisa menjadi media belajar bagi pelajar untuk mempelajari bagaimana cara kerja turbin angin menghasilkan listrik sehingga dapat digunakan seharihari.

\section{Metode Penelitian}

Pada proses penelitian ini memerlukan beberapa tahapan kegiatan yang akan dilakukan. Diagram alir diperlukan untuk mempermudah proses penelitian dapat dilihat pada Gambar 1.

Dalam penelitian ini metode yang digunakan adalah perancangan, yaitu penelitian yang dilakukan dengan melakukan perhitungan dan simulasi pada perangkat lunak QBlade. Dalam penelitian ini, penulis melakukan pengumpulann data dari beberapa referensi berupa kecepatan angin, jurnal terkait, buku, tesis dan karya ilmiah. Dalam simulasi, parameter yang telah ditentukan serta airfoil yang telah ditentukan di simulasikan menggunakan aplikasi QBlade hingga menghasilkan bentuk airfoil, koefisien angkat $(\mathrm{Cl})$, koefisien drag (Cd), Tip Speed Ratio (TSR), dan koefisien daya (Cp). 


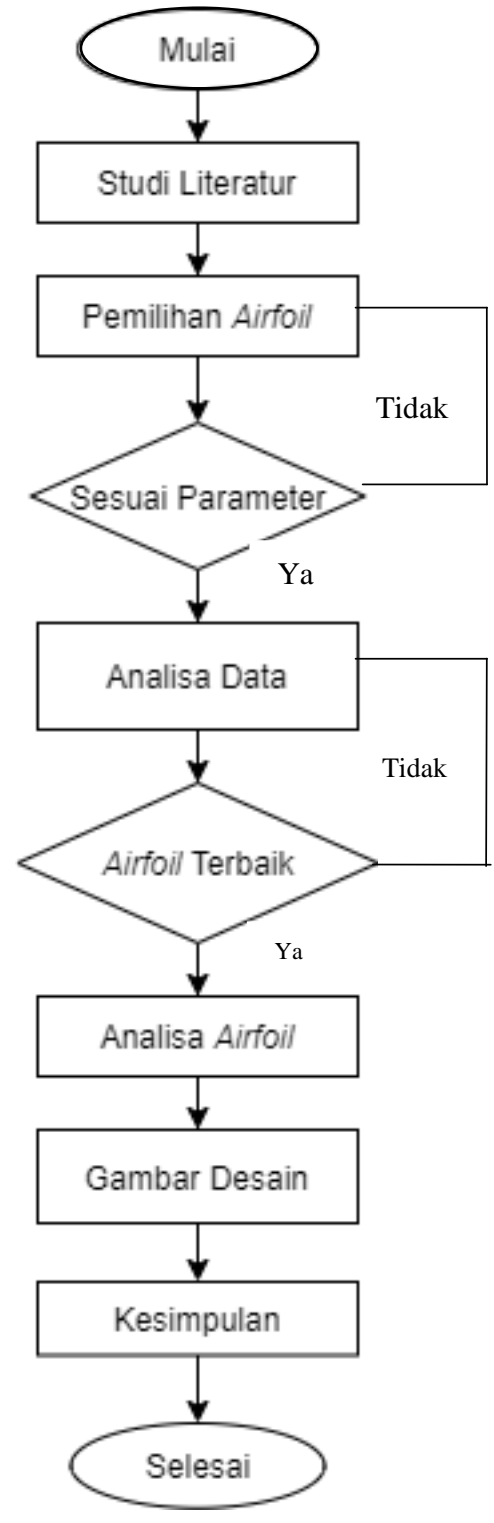

Gambar 1. Diagram Alir Penelitian

\subsection{Identifikasi Masalah}

Perancangan dimulai dengan melakukan identifikasi masalah meliputi kecepatan angin, macam-macam jenis NACA (National Advisory Committe for Aeronauthics), daerah penelitian dan penelitian sebelumnya. Jenis bilah dan jenis NACA pada penelitian sebelumnya menjadi referensi untuk perancangan ini.

\subsection{Gambar Desain}

Setelah melakukan identifikasi masalah di lapangan, maka didapatkan ide untuk mengatasi masalah tersebut. selanjutnya dilakukan penentuan jenis NACA yang akan digunakan. Gambar NACA yang akan digunakan ditunjukkan pada Gambar 2 .

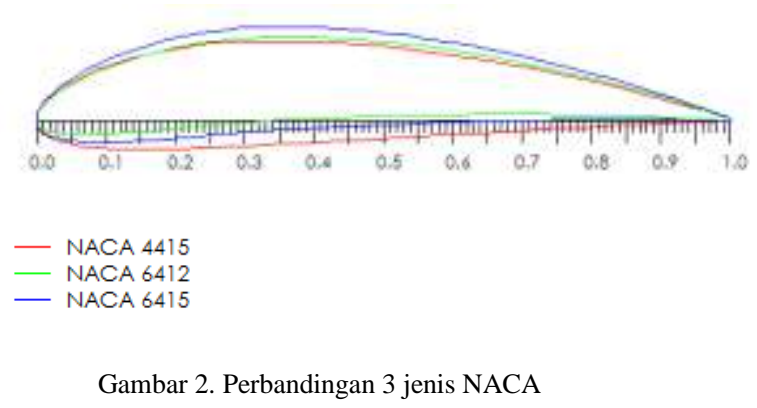

\section{Hasil dan Pembahasan}

Awal perencanaan untuk perancangan bilah turbin angin ini adalah mencari kecepatan angin pada daerah yang dituju yaitu pesisir Cirebon atau pantai yang ada di Cirebon. Kecepatan angin yang terdapat pada laman online Badan Meteorologi Klimatologi dan Geofisika (BMKG) kemudian ditentukan rata-rata angin per-bulan kemudian rata-rata angin tertinggi digunakan dalam perancangan. Gambar 3 merupakan gambar tabel dari data kecepatan angin tertinggi Kota Cirebon pada bulan Oktober

\begin{tabular}{|c|c|}
\hline Tanggal & ff avg \\
\hline $01-10-2020$ & 3 \\
\hline $02-10-2020$ & 4 \\
\hline $03-10-2020$ & 4 \\
\hline $04-10-2020$ & 8 \\
\hline $05-10-2020$ & 9 \\
\hline $06-10-2020$ & 9 \\
\hline $07-10-2020$ & 5 \\
\hline $08-10-2020$ & 4 \\
\hline $09-10-2020$ & 4 \\
\hline $10-10-2020$ & 4 \\
\hline $11-10-2020$ & 3 \\
\hline $12-10-2020$ & 4 \\
\hline $13-10-2020$ & 4 \\
\hline $14-10-2020$ & 4 \\
\hline $15-10-2020$ & 3 \\
\hline $16-10-2020$ & 3 \\
\hline $17-10-2020$ & 3 \\
\hline $18-10-2020$ & 4 \\
\hline $19-10-2020$ & 4 \\
\hline $20-10-2020$ & 4 \\
\hline $21-10-2020$ & 3 \\
\hline
\end{tabular}

Gambar 3. Kecepatan rata-rata angin Cirebon pada bulan Oktober [9]

Data kecepatan rata-rata angin udah tersedia pada laman online milik BMKG sehingga tidak perlu menghitung terlebih dahulu. Kemudian dilakukan desain pada QBlade dengan memasukkan jenis NACA. Bentuk dari masing-masing NACA dapat dilihat pada Gambar 4 - Gambar 6. 


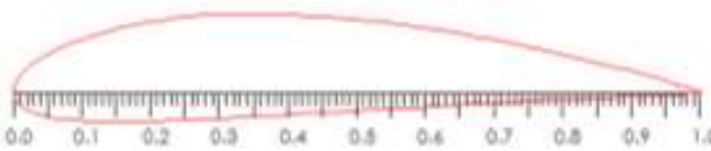

Gambar 4. Airfoil NACA 4415

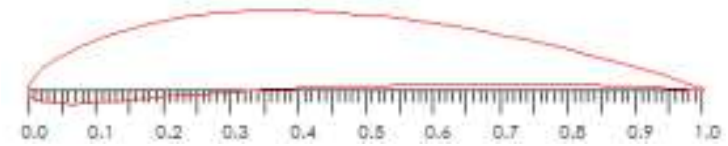

Gambar 5. Airfoil NACA 6415

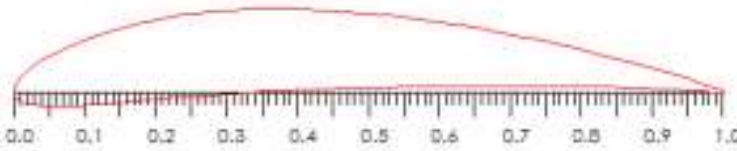

Gambar 6. Airfoil NACA 6415

Pada Gambar 4, Gambar 5, dan Gambar 6 didapatkan informasi tentang Airfoil NACA 4415 memiliki chamber $4 \%$ pada $39.50 \%$, dan ketebalan sebesar $15 \%$ pada 29.10. Sedangkan pada airfoil NACA 6415 camber $6 \%$ terletak pada $39.5 \%$ dan ketebalan sebesar $15 \%$ pada 29.10 terakhir pada airfoil NACA 6412 camber $6 \%$ terletak pada $39.5 \%$ dan ketebalan sebesar $12 \%$ pada 29.10 . Besarnya sudut serang yang merupakan sudut datangnya angin pada airfoil dan gaya angkat yang harus lebih besar dari gaya tahan pada bilah, agar bilah dapat berputar. Airfoil yang memiliki $\mathrm{Cl} / \mathrm{Cd}$ tertinggi artinya pengaruh gaya angkatnya lebih besar dari gaya dorong sehingga bilah dapat berputar. Perbandingan dari $\mathrm{Cl} / \mathrm{Cd}$ terhadap alpha dan perbandinnga $\mathrm{Cl}$ terhadap alpha dapat dilihat pada Gambar 7 dan Gambar 8

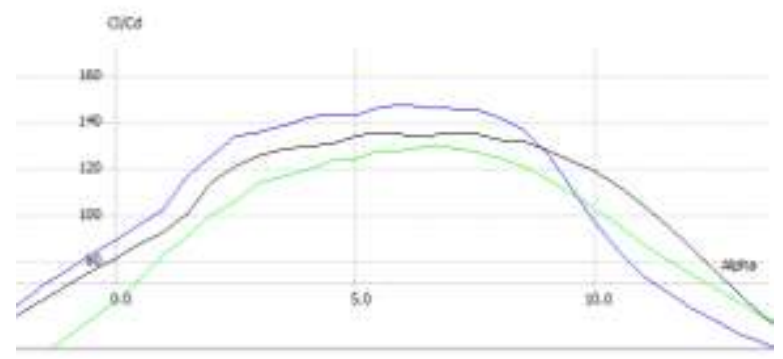

NACA 4415 TI_Re1.000_M0.00_N9.0
NACA 6412 2 TI_Re1.000_M0.00_N9.0
NACA 6415 TI_Re1.000_M0.00_N9.0

Gambar 7. Grafik $\mathrm{Cl} / \mathrm{Cd}$ dari 3 jenis NACA

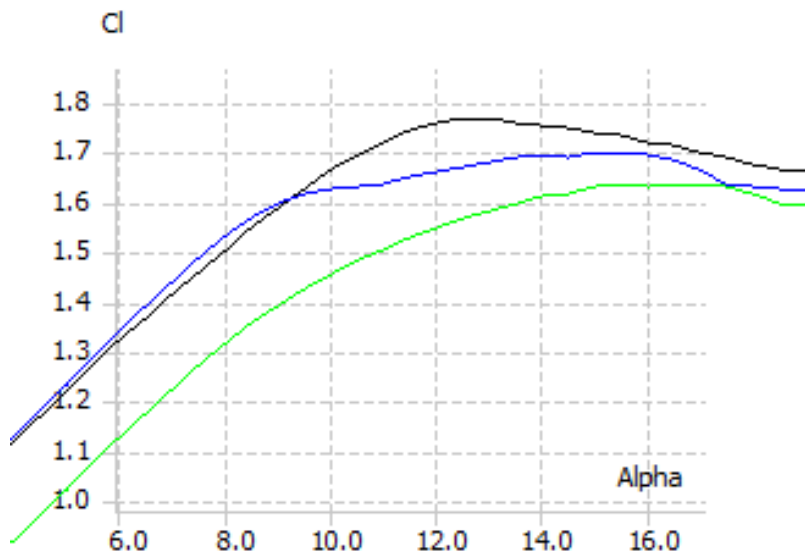

Gambar 8. Grafik $\mathrm{Cl}$ terhadap alpha dari 3 jenis NACA

Jenis airfoil yang memiliki cl/cd tertinggi artinya memiliki nilai angkat yang tinggi didapatkan urutan airfoil yang memiliki nilai angkat tertinggi sampai terendah yaitu NACA 6412, NACA 6415 NACA 4415. Pada tabel dibawah ini dijelaskan nilai $\mathrm{Cl} / \mathrm{Cd}$, alpha dan $\mathrm{Cl}$ pada setiap masing-masing NACA. Tabel 1 dibawah merupakan tabel nilai $\mathrm{Cl} / \mathrm{Cd}, \mathrm{Cl}$ dan alpha dar setiap airfoil.

Tabel 1. Nilai Cl/Cd, Cl dan Alpha setiap airfoil

\begin{tabular}{|c|c|c|c|c|}
\hline TSR & Airfoil & $\mathrm{Cl} / \mathrm{Cd}$ & $\mathrm{Cl}$ & Alpha \\
\hline 7 & $\begin{array}{c}\text { NACA } \\
4415 \\
\end{array}$ & 129.0 & 1.63 & 16.5 \\
\hline 7 & $\begin{array}{c}\text { NACA } \\
6412\end{array}$ & 147.1 & 1.70 & 15.5 \\
\hline 7 & $\begin{array}{c}\text { NACA } \\
6415\end{array}$ & 135.5 & 1.63 & 13 \\
\hline
\end{tabular}

Dalam perancangan ini digunakan parammeter Tip speed ratio yang merupakan suatu perbandingan kecepatan angin terhadap kecepatan bilah, nilai Tip speed ratio secara umum dipengaruhi oleh jumlah bilah yang akan digunakan. Pada perancangan ini menggunakan sebanyak 3 buah bilah yang berdasarkan referensi nilai TSR pada bilah yang berjumlah 3 buah memiliki nilai TSR 6-8, maka pada penelitian ini menggunakan TSR bernilai 7 .

Perancangan bilah taperless yang akan digunakan sebagai uji simulasi terhadap airfoil ditentukan dari parameter utama seperti TSR, efisiensi, daya angin, kecepatan angin maksimum, luas penampang dan jarijari bilah yang akan digunakan menjadi parameter hitung dalam perancangan geometri bilah. Parameter yang dihitung serta parameter yang ditentukan dapat dilihat pada Tabel 2 . 
Shinta Dwi Oktaviani ${ }^{1}$, Reza Setiawan ${ }^{2}$ Farradina Choria Suci ${ }^{3}$

Jurnal Teknik Mesin (JTM) Vol . 14 No. 2 (2021) 118 - 124

Tabel 2. Parameter yag dihitung dan ditetapkan

\begin{tabular}{|c|c|c|c|c|c|}
\hline $\begin{array}{c}\text { Daya } \\
\text { listrik }\end{array}$ & \multicolumn{5}{|c|}{ Efisiensi } \\
\hline watt & $\begin{array}{c}\text { Bila } \\
\mathrm{h}\end{array}$ & Generator & Transmisi & Controller & Total \\
\hline \multirow{2}{*}{500} & 0,2 & 0,9 & 0,9 & 0,9 & 0,162 \\
\cline { 2 - 4 } & 0,4 & & & 0,324 \\
\hline
\end{tabular}

\begin{tabular}{|c|c|c|c|c|c|}
\hline \multirow[t]{2}{*}{$\begin{array}{l}\text { Daya } \\
\text { Angin }\end{array}$} & $\begin{array}{c}\text { Kecepatan } \\
\text { Angin }\end{array}$ & $\begin{array}{c}\text { Masa } \\
\text { Jenis } \\
\text { Udara } \\
\end{array}$ & $\begin{array}{c}\text { Luas } \\
\text { Sapuan } \\
\text { Area } \\
\end{array}$ & $\begin{array}{c}\text { Jari- } \\
\text { Jari }\end{array}$ & \multirow{2}{*}{$\begin{array}{c}\text { Jari Jari } \\
\text { yang } \\
\text { digunakan } \\
\text { (m) }\end{array}$} \\
\hline & $(\mathrm{m} / \mathrm{s})$ & $\left(\mathrm{kg} / \mathrm{m}^{3}\right)$ & $\left(\mathrm{m}^{2}\right)$ & (m) & \\
\hline 3086,42 & 9 & \multirow{2}{*}{1,220} & 6,91 & 1,48 & \multirow{2}{*}{1,02} \\
\hline 1543,21 & 9 & & 3,46 & 1,05 & \\
\hline
\end{tabular}

Parameter yang ditentukan antara lain adalah daya listrik, efisiensi bilah, efisiensi generator, efisiensi transmisi, efisiensi controller, kecepatan angin, massa jenis udara dan jari-jari yang digunakan. Sementara itu parameter yang harus dihitung adalah efisiensi total, daya angin, luas sapuan area, dan jari-jari. Parameter yang ditentukan dan parameter hitung diatas digunakan untuk merancang desain bilah yang selanjutnya diteruskan pada aplikasi QBlade. Berdasarkan perhitungan pada Tabel 2 didapatkan bentuk geometri bilah jenis taperless yang digunakan sebagai uji simulasi airfoil sebagaimana terlihat pada Gambar 9

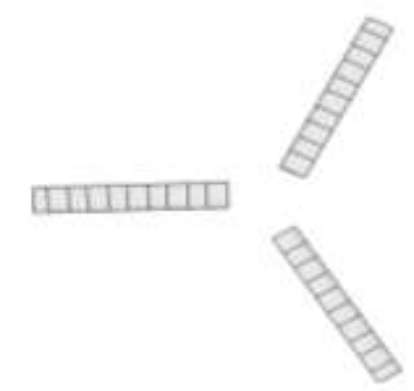

Gambar 9. Geometri bilah jenis Taperless

Pada Gambar 10 dan 11 dapat dilihat bahwa koefisien power pada bilah dengan jenis NACA 4415 adalah sebesar 0.54 terhadap Tip Speed Ratio sebesar 5.0 tanpa loss, sedangkan pada Gambar 10 grafik menunjukkan koefisien power paling tinggi kurang dari 0.50 terhadap TSR tertinggi sebesar 5.5 dengan loss yang terjadi.

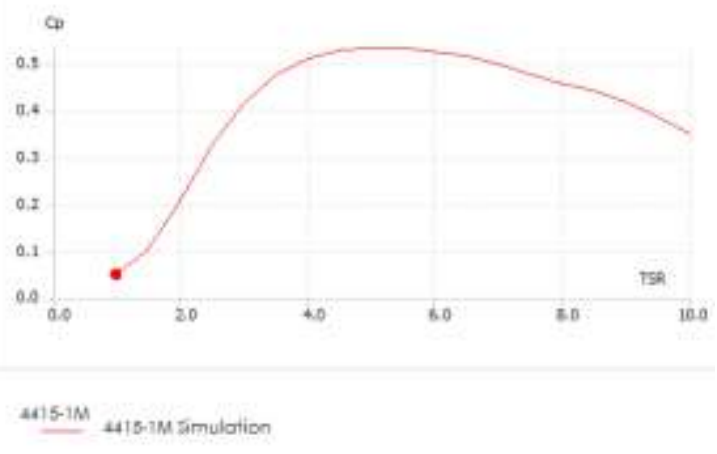

Gambar 10. Grafik Cp terhadap TSR dari NACA 4415

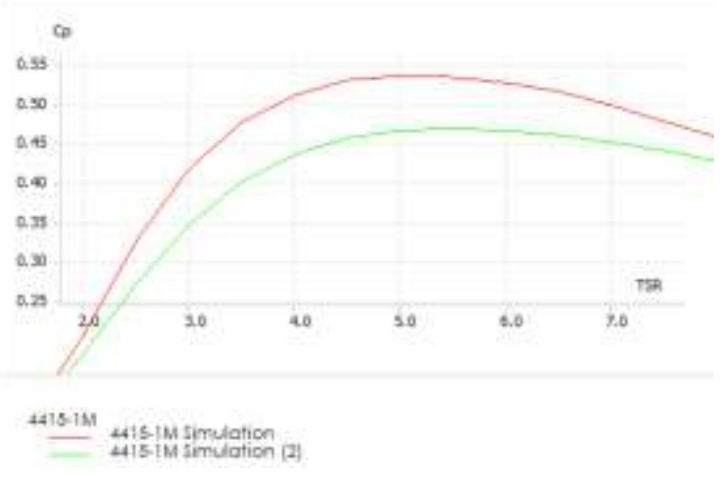

Gambar 11. Grafik Cp terhadap TSR dari NACA 4415 dengan Loss yang ditunjukkan oleh garis hijau

Koefisien daya yang didapatkan oleh bilah dengan jenis NACA 6412 adalah sebesar 0.53 terhadap Tip Speed Ratio sebesar 4.5 tanpa loss, sedangkan pada gambar 13 grafik menunjukkan koefisien daya paling tinggi kurang dari 0.46 terhadap TSR tertinggi sebesar 4.5 dengan loss yang terjadi. Grafik dapat dilihat pada Gambar 12 dan Gambar 13

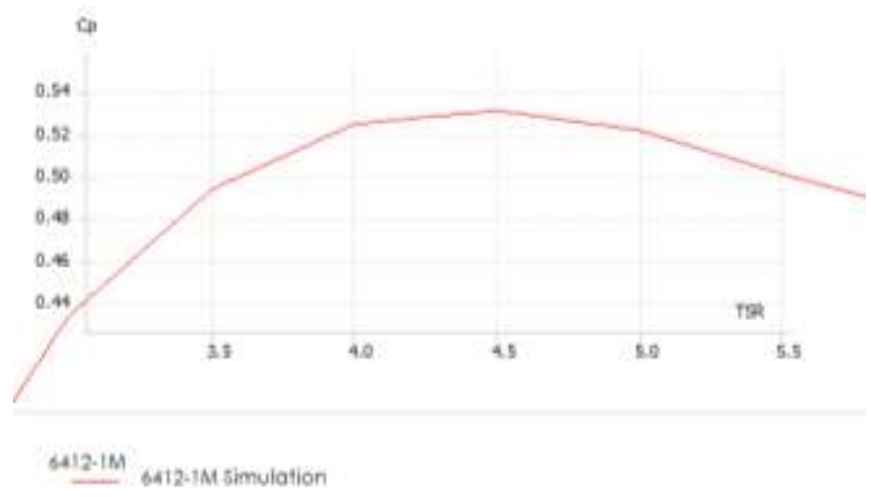

Gambar 12. Grafik Cp terhadap TSR dari NACA 6412 
Shinta Dwi Oktaviani ${ }^{1}$, Reza Setiawan², Farradina Choria Suci ${ }^{3}$

Jurnal Teknik Mesin (JTM) Vol . 14 No. 2 (2021) 118 - 124

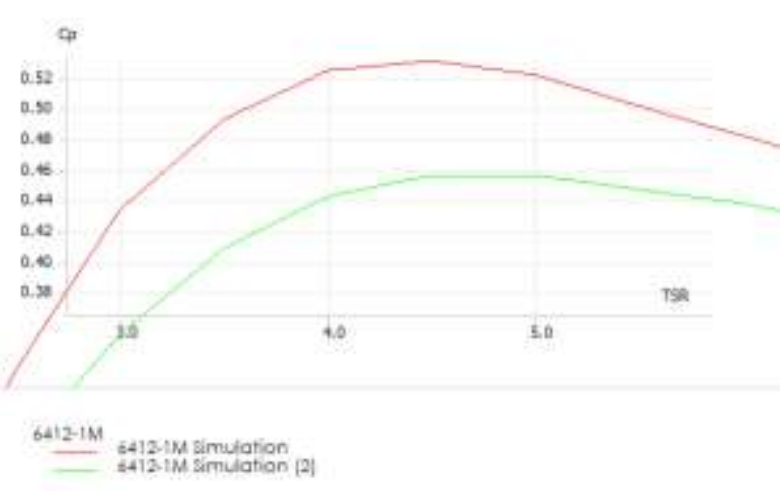

Gambar 13. Grafik Cp terhadap TSR dari NACA 6412 dengan Loss yang ditunjukkan oleh garis hijau

Koefisien daya yang didapatkan oleh bilah dengan jenis NACA 6415 adalah sebesar 0.53 terhadap Tip Speed Ratio sebesar 4.5 tanpa loss, sedangkan pada gambar 15 grafik menunjukkan koefisien daya paling tinggi pada 0.46 terhadap TSR yang stabil pada 4.5 hingga 5.0 dengan loss yang terjadi. Grafik dapat dilihat pada Gambar 14 dan Gambar 15

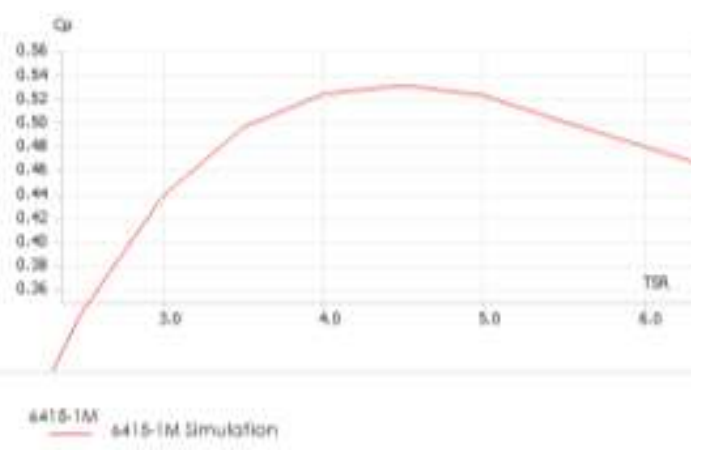

Gambar 14. Grafik Cp terhadap TSR dari NACA 6415

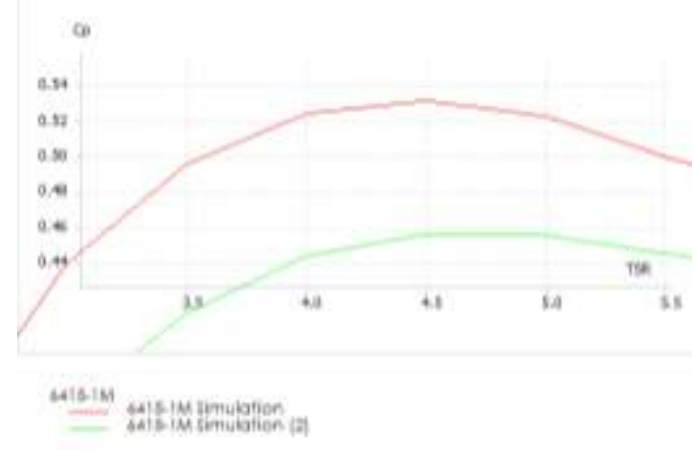

Gambar 15. Grafik Cp terhadap TSR dari NACA 6415 dengan Loss yang ditunjukkan oleh garis hijau

Pada Gambar diatas menjelaskan hubungan antara koefisien daya dengan keadaan Tip Speed Ratio (TSR). Berdasarkan simulasi rotor pada setiap airfoil yang ditampilkan pada grafik, terlihat bahwa airfoil NACA 4415 memiliki nilai Cp terhadap TSR tertinggi dan konstan. Nilai grafik yang didapatkan oleh NACA 4415 tersebut bernilai 0.5 pada TSR 5 dengan los yang terjadi. Pada dasarnya NACA 6412, NACA 6415, dan NACA 4415 memiliki nilai Cp dan TSR yang mendekati. Nilai Cp dan TSR terendah diperoleh NACA 6415. Berdasarkan simulasi yang dilakukan sebelumnya, jika membandingkan setiap jenis airfoil yang mempunyai nilai koefisien daya paling besar unntuk turbina ngin tipe horizontal jenis taperless yang memiliki bilah sebanyak 3 dan di desain untuk TSR 7 adalah NACA 4415 yaitu sebesar 0.5 atau efisiensinya sebesar 50\%. Dan yang memiliki efisiensi paling rendah adalah NACA 6415 yaitu dengan koefisien daya sebesar 0.46 dan TSR pada 4.5 .

Pada perancangan bilah untuk pesisir Cirebon digunakan airfoil NACA untuk mendesain bentuk airfoil yang digunakan. Mengunnakan 3 jenis NACA yaitu NACA 4415, NACA 6412 dan NACA 6415 yang disimulasikan terhadap rata-rata kecepatan angin tertinggi yang penah terjadi di pesisir Cirebon selama 11 bukan terhitung bulan Januari hingga bulan November 2020 dari Badan Meteorologi Klimatologi dan Geofisika (BMKG) daerah setempat. Digunakan jenis NACA 4 angka dimana angka pada seri pertamanya merupakan maksimum camber dalam perseratus chord, angka keduanya adalah posisi dari makssimum camber pada chord line dalam sepersepuluh dari leading edge, da pada dua angka terakhir adalah ketebalan maksimum dalam seper seratus chord. Jadi pada NACA 4415 memiliki maksimum camber sebesar 4, lalu memiliki maksimum camber pada chord line sebesar 4 dan terakhir memiliki ketebalan maksimum 15 dalam seperseratus chord.

NACA yang sudah ditentukan selanjutnya di simulasikan pada aplikasi QBlade untuk mengetahui bentuk dari NACA tersebut dan untuk mengetahui nilai dari koefisien angkat $(\mathrm{Cl})$ dan nilai koefisien drag (Cd) terhadap alpha. Setelah mendapatkan $\mathrm{Cl} / \mathrm{Cd}$ terhadap alpha, nilai tersebut di input kedalam parameter yang tak dihitung di dalam Microsoft Excel yang selanjutnya digunakan untuk melakukan perhitungan dalam perancangan bilah. Nilai hasil dar perhitungan pada Microsoft Excel nantinya masuk kedalam perhitungan parameter yang diguunakan untuk merancang setiap elemen bilah. Dalam perancangan bilah ini digunakan Tip Speed Ratio (TSR) sebesar 7, dimana TSR merupakann suatu perbandingan antara kecepatan angin dan kecepatan bilah. Penggunaan TSR secara umum dipengaruhi oleh jumlah bilah yang digunakan, pada perancangan inimenggunakan bilah yang berjumlah 3 dimana berdasarkan referensi TSR yang biasa digunakan oleh peranangan dengan 3 bilah adalah TSR 6-8. Maka pada perancangan ini digunakan TSR yang bernilai 7 [11] 
Pada tahap selanjutnya dilakukan perhitungan dengan parameter hitung dan parameter yang ditentukan. Parameter yang ditentukan antara lain adalah daya listrik, efisiensi bilah, efisiensi generator, efisiensi transmisi, efisiensi transmisi, efisiensi controller, kecepatan angin, jari-jari yang digunakan dan luas sapuan area. Pada perhitungan yang menggunakan Microsoft Excel digunakan nantinya untuk menentukan nilai dari elemen-elemen pada bilah. Parameter yang dihitung antara lain adalah efisiensi total, daya angin yang didapatkan, luas sapuan area dan jari-jari. Semua yang dihitung dan yang tak dihitung pada Microsoft Excel adalah bertujuan untuk perancangan bilah dan memudahkan perancang dalam merancang bilah pada aplikasi QBlade. Setelah melakukan perhitungan, maka dapat dilakukan perancangan elemen bilah dengan memasukkan nilai jari-jari parsial, chord, twist, dan airfoil. Desain rotor dari NACA 4415,NACA 6412 dan NACA 6415 berbentuk sama karena memiliki chord dan twist yang sama. Yang membedakan dari hasil ketiga airfoil NACA tersebut adalah koefisien daya nya terhadap Tip Speed ratio.

\section{Kesimpulan}

Kesimpulan yang diapatkan dari penelitian ini berdasarkan uraian yang telah dijelaskan sebelumnya, NACA terbaik yang digunakan adalah jenis NAA 4415 yang memiliki nilai $\mathrm{Cp}$ 0,49 atau 49\% dan daya maksimum $746 \mathrm{~W}$. Hasil penelitiaan ini dapat digunakan untuk membuat rancang bangun dari bilah turbin angin yang akan digunakan pada pesisir pantai utara Jawa Barat.

\section{Daftar Rujukan}

[1] Arga, G.S, Untung, B, Ahmad, F.Z., 2016. Analisa efektifitas Wind Turbine sumbu horizontal dengan Variasi Jumlah dan Jenis Airfoil Sebagai Sumber Energi Listrik Tambahan pada Fisheries Inspection, 4 (4), 838-839.

[2] Triyani., 2017. Energi Terbarukan Tenaga Angin. 1st ed. PT.Perca

[3] Maidi, A., 2016. Kajian Literatur Sudu Turbin Angin untuk Skala Kecepatan Angin Rendah, Jurnal Mekanova, 2 (1), 74 83

[4] Sumiati,Ruzita dkk. 2014. Rancang bangun micro turbin angin pembangkit listrik untuk rumah tinggal di daerah kecepatan angin rendah. Prosiding Semnastek ISSN : 2407 1846

[5] Hicary dkk., 2016. Analisis pengaruh jumlah sudu pada turbin angin savonius sumbu vertikal terhadap tegangan dan arus di dalam proses pengisan akumulator, 3 (3), $\quad 4912$.

[6] Alfaridzi, A, Reza S., 2020, Analisis Performa Bilah Taperless Dengan Airfoil NACA 4412 Pada Horizontal Axis Wind Turbine TSD 500 Di PT Lentera Bumi Nusantara, Jurnal Teknik Mesin dan Pembelajaran 3 (2), 64-73.

[7] Rachman dkk., 2019. Rancang Bangun dan Uji Prestasi Horizontal Axis Wind Turbine jenis Taper, 9 (2), 4911-4918.

[8] Xingxing, L, Lei, Z, Juanjuan, S, Fengjiao, B, Ke, Y., 2019. Airfoil Design for Large Horizontal Axis Wind Turbines in Low Wind Speed Regions, 2345-2357

[9] Kota Cirebon, 2021. Profil daerah Kota Cirebon. [Online] (Update 6 Januari 2021) Tersedia di : https://jabarprov.go.id/index.php/pages/id/1061 [Accessed 13 Jun 2021]

[10] Badan Meteorologi Klimatologi dan Geofisika (BMKG), 2021. Kecepatan angin pada Stasiun Pos Meteorologi Penggung. [Online] (Update 6 Januari 2021) Tersedia di : https://www.bmkg.go.id [Accesed 1 Jun 2021]

[11] Zahra, I., 2018. Dasar -dasar Perancangan Bilah. Tasikmalaya, Jawa Barat 2 Juni 2018. Jawa Barat 